\title{
Inter-Relações entre Valores Pessoais e Valores Laborais de Jovens Universitários na Cidade de São Paulo
}

\author{
Inter-Relations between Personal Values and Labor Values of University \\ Students in the City of São Paulo
}

Silmara Cristiane Gomes ${ }^{\mathrm{I}}$

\section{Resumo}

Este trabalho de pesquisa tem como objetivo geral caracterizar as inter-relações entre valores pessoais e valores laborais de jovens universitários na cidade de São Paulo. Realizou-se análises estatísticas para a verificação dos objetivos e revisão bibliográfica para possibilitar a compreensão dos elementos que influenciam na inter-relação entre valores pessoais e valores laborais. Considera-se, ao longo deste trabalho, que as inter-relações estabelecidas seguem padrões e demostram mudanças, em alguns aspectos, em relação às teorias preconizadas.

Palavras-chave: Valores Pessoais; Valores Laborais.

\begin{abstract}
The general objective in this research is to characterize the interrelationships between Personal Values and Labor Values of university students in the city of São Paulo. Statistical analyzes were performed to verify the objectives and a literature review was made to enable understanding of the elements that influence the interrelation between Personal Values and Labour Values. Is considered throughout this work, that the interrelations established follow patterns and some aspects show changes in relation to the theories recommended.
\end{abstract}

Keywords: Personal Values; Labour Values.

\footnotetext{
${ }^{1}$ gomessilmara@hotmail.com, Brasil. Professora no Centro Universitário Senac - SENAC. Doutora em Administração pela Pontifícia Universidade Católica de São Paulo - PUC-SP. Av. Engenheiro Eusébio Stevaux, 823, Santo Amaro, CEP: 04696-000 - São Paulo, SP - Brasil.
} 


\section{Introdução}

Nos últimos anos, tem se tornado mais comum e frequente as reflexões em relação às formas como o ser humano se relaciona com ele e com o outro, além das características sociais de cada época, as afirmativas em relação à diferença de comportamento entre a sociedade atual e a sociedade pós-revolução industrial cresceram, tomaram forma e ocuparam pesquisas e pesquisadores.

Independentemente do nome que se queira atribuir ao novo momento da sociedade, se o correto ou oportuno é chama-la de sociedade pós-moderna, ou sociedade de consumo ou cultura de consumo, não se pretende aqui julgar. Nesse momento se faz relevante observar que algo mudou e que não é possível considerar que as mesmas estratégias de produção, comercialização, consumo e trabalho se mantiveram inalteradas ao longo do último século.

Tem se vários motivadores para tais mudanças e os valores fazem parte desse leque de influenciadores e influenciados.

Schwartz (2006) define valores como metas desejáveis e transituacionais, que variam em importância, servindo como princípios na vida de uma pessoa ou de uma entidade social. Está implícito nessa definição que os valores podem motivar ações dando direção e intensidade emocional, no entanto, os valores nem sempre são os mesmos para os diferentes âmbitos da vida.

Segundo Sagie e Elizur (I996), os valores guiam as atitudes e o comportamento das pessoas e podem se relacionar com pontos específicos da vida do indivíduo, formando assim estruturas inter-relacionadas. A maioria das pessoas tem uma estrutura de valores que guia a sua vida de maneira geral, mas para questões específicas da vida, como o trabalho, as pessoas apresentam uma outra estrutura de valores.

Estruturas inter-relacionadas, mas com características específicas. Os valores auxiliam na compreensão de questões sociais, pessoais e de trabalho. Sendo assim, é possível que se tenha valores voltados para o trabalho, focados em acumulação de capital e aspectos econômicos racionais fortes, e na estrutura geral de valores, ter aspectos fortes de busca de prazer e satisfação com a vida.

Essas gamas de estruturas de valores podem ser relacionadas, via difusão ou compensação. Alguns autores, como Elizur e Sagie (r999) e Porto e Tamayo (2007),

\section{Revista Administração em Diálogo} ISSN 2178-0080 
apoiam de forma mais explícita as relações de difusão, as quais significam que o que é valorizado em uma gama da vida também será em outra.

O estudo de Elizur e Sagie (1999) ressalta que a relação entre valores gerais e valores específicos, como os valores laborais, pode dar-se de duas maneiras, ou por difusão ou por compensação. No caso de difusão, o que é valorizado de maneira geral também é valorizado nas áreas específicas da vida. Por exemplo, se a pessoa valoriza o sucesso pessoal na sua vida, ela buscará no trabalho, alcançar o sucesso profissional. No caso de compensação, o que é valorizado em um âmbito não o é em outro. Por exemplo, se a pessoa valoriza novidades e desafios em sua vida, no trabalho ela buscaria segurança. As pesquisas têm oferecido apoio para a hipótese de difusão. No entanto, Elizur e Sagie sugerem que esse tópico deve ser objeto de investigação. (Porto, \& Tamayo, 2007, p. 64).

Os valores são aspectos importantes na formação dos indivíduos, discutir suas inter-relações pode auxiliar as organizações a compreender relações de trabalho e convívio. Considerando os pontos apresentados, tem-se como objetivo geral desta pesquisa caracterizar as inter-relações entre valores pessoais e valores laborais de jovens universitários na cidade de São Paulo.

\section{Valores Pessoais Sob a Perspectiva de Schwartz}

Os valores pessoais podem ser compreendidos como a expressão de compromissos individuais relativos a critérios normativos que envolvem questões cognitivas, avaliativas e de responsabilidade pessoal, limitando suas escolhas.

A pessoa é motivada a agir guiada por três critérios - cognitivos, catéticos e avaliativos - e também pelas orientações de valor que a obrigam a respeitar certas normas que limitam suas escolhas. Portanto, os valores das pessoas são compromissos com esses critérios normativos e apresentam três aspectos cognitivos, avaliativos e de responsabilidade pessoal - diante das consequências de suas ações, tanto para a pessoa que age como para o sistema social. (Ros, 2006, p. 27).

Os valores têm estruturas determinadas que auxiliam na compreensão do peso atribuído à determinada ação. Os valores guiam as ações considerando as consequências desses atos em relação a si e a sociedade.

Compreender os valores auxilia na identificação de preditores de comportamento e pode-se, dessa forma, estabelecer possibilidades de ação e comportamento de um grupo de indivíduos.

\section{Revista Administração em Diálogo} ISSN 2178-0080 
Portanto os valores são úteis em dois aspectos básicos. A nível individual, aportam uma importante informação sobre os comportamentos, atitudes e identidades das pessoas. Os perfis de valores das pessoas são importantes preditores de comportamento, interesses e atitudes, por exemplo, o rendimento acadêmico dos estudantes, os vínculos interpessoais ou a conduta no voto. Aqui é necessário considerar que os valores se encontram no cume da personalidade como o constructo que orienta todas as ações das pessoas. (Castro Solano, \& Nader, 2006, p. I59).

O estudo dos valores possibilita, portanto, que se identifique o constructo orientador das ações das pessoas. As decisões e ações passam por aquilo que os indivíduos entendem como prioridade e pelo o que estão dispostos a fazer, segundo o seu conjunto de valores.

A partir da compreensão da importância do estudo dos valores e de sua influência para a compreensão de ações e comportamentos, passa-se a ter a necessidade de uma definição que consiga abarcar todas as características e traços marcantes do tema.

Sendo assim, os estudos sobre os valores conseguiram caracterizar cinco traços de definição conceitual sobre o tema, como apresenta Schwartz (2006, p. 56):

Há um grande acordo na bibliografa sobre cinco traços da definição conceitual dos valores. Um valor é: I) uma crença; 2) que pertence a fins desejáveis ou a formas de comportamento; 3) que transcende as situações específicas; 4) que guia a seleção ou avaliação de comportamentos, pessoas e acontecimentos; e 5) que se organiza por sua importância relativa a outros valores para formar um sistema de prioridades de valores.

A definição de valores indica questões importantes sobre o tema, tais como o fato de que os valores são crenças que pertencem a formas de comportamento ou a fins desejáveis, ou seja, os valores são estabelecidos por aspectos culturais. Os valores vão além de questões pontuais e podem ser relevantes em ações gerais, eles guiam pessoas, comportamentos e acontecimentos, ou seja, são diretivos, são guias de ação, e por último os valores se reorganizam em relação as suas respectivas importâncias para o indivíduo e para o momento que vive.

Schwartz (I987 e 1992) conseguiu auxiliar na progressão dos estudos sobre valores, iniciados por Rokeach (1973), encontrando pontos obscuros na Rockeach Value Survey (RVS) e criando a Schwartz Value Survey (SVS). No entanto, ele se preocupou em agrupar ao seu trabalho valores que haviam sido elaborados por Rokeach.

\section{Revista Administração em Diálogo} ISSN 2178-0080 
Segundo as pesquisas de Schwartz, os valores devem representar as respostas que as pessoas e os grupos elaboram em relação a três requisitos universais: as necessidades básicas dos indivíduos como seres biológicos, a coordenação dos indivíduos como seres sociais e o funcionamento correto e a sobrevivência dos grupos. Esses requisitos juntos e a consideração da universalidade dos tópicos possibilita a fundamentação da teoria.

A teoria de Schwartz respeita as teorias e os desenvolvimentos anteriores, os engloba na medida do possível e permite avanços, considerando que ela tem sido frequentemente revisitada.

A teoria de Schwartz propõe uma síntese das contribuições anteriores num modelo que estabelece os valores como objetivos gerais que visam à satisfação de necessidades humanas básicas, organizando-se em dez tipos motivacionais que definem todo o espectro axiológico humano. Para operacionalizar a sua teoria, o autor desenvolveu originalmente a escala Schwartz Value Survey (SVS), tendo apresentado recentemente uma proposta alternativa para estudar empiricamente o sistema de valores humanos por meio de uma nova escala: o portrait value questionnaire (PVQ). Essa nova escala, proposta pelo autor em 20OI e sujeita a sucessivas revisões, pretende simplificar o processo de inquirição sobre valores humanos, diminuindo o tempo de resposta exigido, facilitando a compreensão das perguntas e recorrendo ao questionamento projetivo sobre condutas e posturas concretas perante diversos aspectos da vida em sociedade. (Almeida, \& Sobral, 2009, p. IO4).

A Schwartz Value Survey foi desenvolvida e testada objetivando o estudo do sistema de valores de forma universal. O autor identificou pontos de atenção na escala e principalmente limitações relativas à universalidade e elaborou a Portrait Value Questionnaire, que possui o mesmo objetivo e busca reduzir alguns dos viesses identificados pelo pesquisador.

Após responder o Schuartz Value Survey ou o Portrait Value Questionnaire, pode-se enquadrar os indivíduos, segundo suas respostas, na escala de Valores Pessoais de Schwartz que conta com dez tipos motivacionais. Na Figura I, se pode observar os dez tipos motivacionais, visualizar exemplos e entender quais são os principais originadores ou fontes destes tipos de valor. São consideradas fontes dos tipos motivacionais de valor:

I) Organismo: equivale às necessidades universais dos indivíduos como organismos biológicos;

\section{Revista Administração em Diálogo} ISSN 2178-0080 
2) Interação: equivale aos requisitos universais para a coordenação da interação social;

3) Grupo: equivale aos requisitos universais para o funcionamento tranquilo e à sobrevivência de conjuntos de pessoas.

\begin{tabular}{|c|c|c|}
\hline Definição & Exemplos de Valores & Fontes \\
\hline $\begin{array}{l}\text { Poder: status social sobre as } \\
\text { pessoas e os recursos. }\end{array}$ & $\begin{array}{l}\text { Poder social. Autoridade. } \\
\text { Riqueza. }\end{array}$ & $\begin{array}{l}\text { Interação } \\
\text { Grupo }\end{array}$ \\
\hline $\begin{array}{l}\text { Realização: sucesso pessoal } \\
\text { mediante a demonstração de } \\
\text { competência, segundo critérios } \\
\text { sociais. }\end{array}$ & $\begin{array}{l}\text { Bem-sucedido. Capaz. } \\
\text { Ambicioso. }\end{array}$ & $\begin{array}{l}\text { Interação } \\
\text { Grupo }\end{array}$ \\
\hline $\begin{array}{l}\text { Hedonismo: Prazer e } \\
\text { gratificação sensual para si } \\
\text { mesmo. }\end{array}$ & Prazer. Desfrutar a vida. & Organismo \\
\hline $\begin{array}{l}\text { Estimulação: entusiasmo, } \\
\text { novidade e desafio na via. }\end{array}$ & $\begin{array}{l}\text { Audacioso. Uma vida variada. } \\
\text { Uma vida excitante. }\end{array}$ & Organismo \\
\hline $\begin{array}{l}\text { Autodeterminação: pensamento } \\
\text { independente e escolha da } \\
\text { ação, criatividade, exploração. }\end{array}$ & Criatividade. Curioso. Liberdade & $\begin{array}{l}\text { Organismo } \\
\text { Interação }\end{array}$ \\
\hline $\begin{array}{l}\text { Universalismo: Compreensão, } \\
\text { apreço, tolerância e atenção } \\
\text { com o bem-estar de todas as } \\
\text { pessoas e da natureza. }\end{array}$ & $\begin{array}{l}\text { Tolerância. Justiça social. } \\
\text { lgualdade. Proteção do meio } \\
\text { ambiente }\end{array}$ & $\begin{array}{l}\text { Grupo } \\
\text { Organismo }\end{array}$ \\
\hline $\begin{array}{l}\text { Benevolência: preservação ou } \\
\text { intensificação do bem-estar das } \\
\text { pessoas com as quais se está } \\
\text { em contato pessoal frequente. }\end{array}$ & Ajuda. Honesto. Não rancoroso & $\begin{array}{l}\text { Organização } \\
\text { Interação } \\
\text { Grupo }\end{array}$ \\
\hline $\begin{array}{l}\text { Tradição: respeito, compromisso } \\
\text { e aceitação dos costumes e } \\
\text { ideias oferecidas pela cultura } \\
\text { tradicional ou a religião. }\end{array}$ & $\begin{array}{l}\text { Humilde. Devoto. Aceitar minha } \\
\text { parte na vida }\end{array}$ & Grupo \\
\hline $\begin{array}{l}\text { Conformidade: restrição das } \\
\text { ações, tendências e impulsos } \\
\text { que possam incomodar ou ferir } \\
\text { os outros e contrariar } \\
\text { expectativas ou normas sociais. }\end{array}$ & $\begin{array}{l}\text { Polidez. Obediente. Honra aos } \\
\text { pais e pessoas mais velhas }\end{array}$ & $\begin{array}{l}\text { Interação } \\
\text { Grupo }\end{array}$ \\
\hline $\begin{array}{l}\text { Segurança: segurança, } \\
\text { harmonia e estabilidade da } \\
\text { sociedade, das relações e de si } \\
\text { mesmo. }\end{array}$ & $\begin{array}{l}\text { Segurança nacional. Ordem } \\
\text { social. Idôneo }\end{array}$ & $\begin{array}{l}\text { Organismo } \\
\text { Interação } \\
\text { Grupo }\end{array}$ \\
\hline
\end{tabular}

Figura I - Tipos Motivacionais de Valor.

Fonte: Adaptado de Schwartz (2006).

Esses dez tipos podem ser classificados em quatro tipos motivacionais de segunda ordem que agregam os valores de primeira ordem.

Os tipos motivacionais de segunda ordem são:

I) Autopromoção - que agrega: Poder, Hedonismo e Realização;

\section{Revista Administração em Diálogo} ISSN 2178-0080 
2) Autotranscedência - que agrega: Universalismo e Benevolência;

3) Abertura a mudança - que agrega Hedonismo, Estimulação e Autodeterminação;

4) Conservação - que agrega: Segurança, Conformidade e Tradição.

A Figura 2 apresenta graficamente os tipos motivacionais e representa as formas de aproximação e oposição de cada tipo.

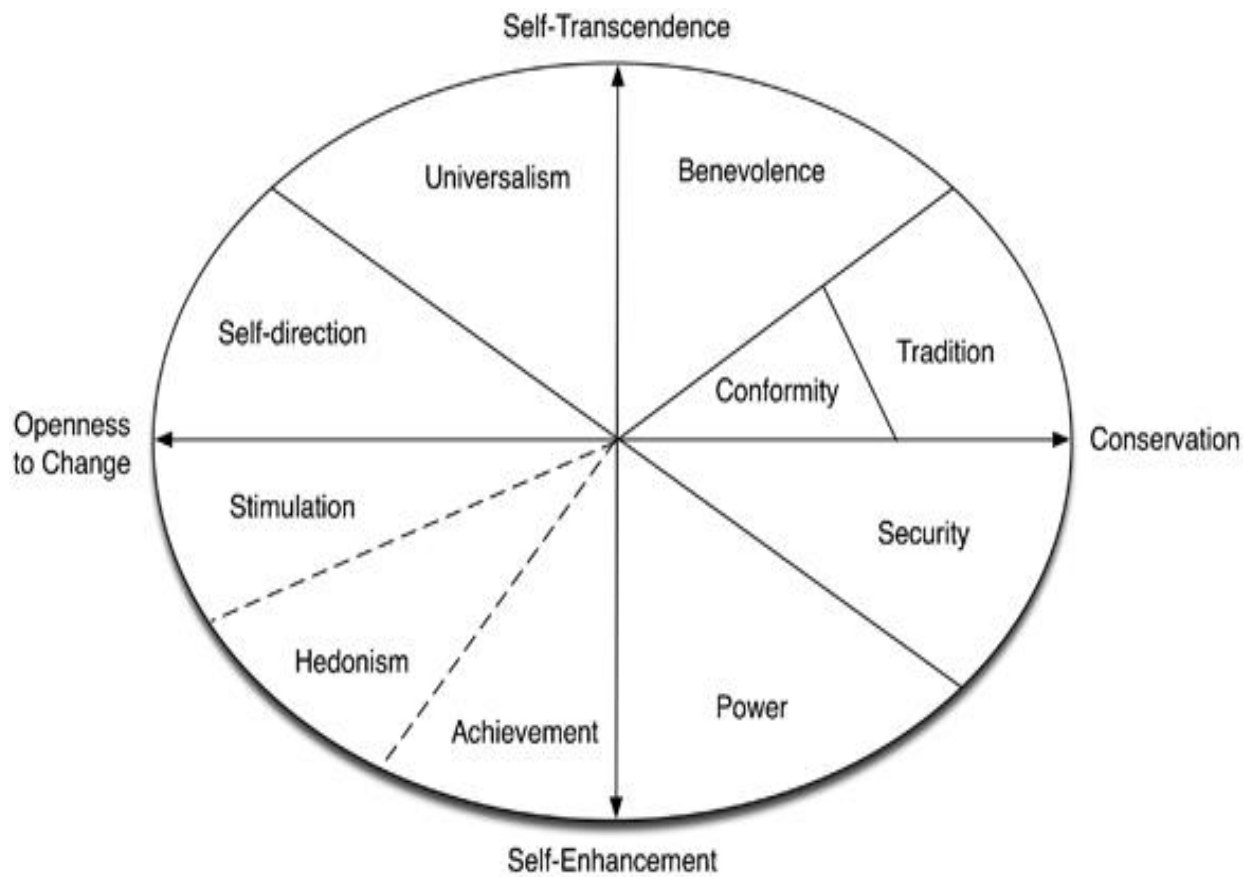

Figura 2 - Tipos de Valores da Teoria Motivacional de Schwartz. Fonte: Schwartz (1992).

Segundo Schwartz (1992), esses valores se inter-relacionam e têm relações de aproximação e afastamento. As ações despendidas para realizar cada tipo de valor têm consequências psicológicas, práticas e sociais que podem entrar em conflito com a realização de outros valores. Por exemplo, ter como prioridade condutas relacionadas a valores de realização, ou seja, busca de êxito pessoal, pode entrar em conflito com valores de benevolência, ou seja, preocupação com o bem-estar dos outros. Os valores, portanto, se ajustam melhor a um modelo circular em que os valores afins estão próximos e valores que não são afins estão posicionados no lado oposto do círculo. Dessa forma, os valores formam um contínuo de motivações relacionadas.

\section{Revista Administração em Diálogo} ISSN 2178-0080 
Os valores motivacionais têm, segundo a teoria, uma relação dinâmica entre si. As ações que buscam alcançar um determinado valor podem ser compatíveis ou conflitantes com a busca de outro valor. Assim, os tipos motivacionais descritos podem ser organizados em uma estrutura circular na qual sejam visíveis as relações de complementaridade e de oposição entre os valores, ou seja, os valores que se situem mais próximos entre si têm motivações subjacentes semelhantes e aqueles que estejam mais distantes no círculo terão motivações subjacentes mais antagônicas. Essa estrutura de valores humanos e a teoria subjacente foram validadas e empiricamente confirmadas por Schwartz ao longo de mais de dez anos de pesquisa. (Almeida, \& Sobral, 2009, p. Io8).

A posição de cada um dos valores na estrutura representa a sua aproximação e o seu afastamento em relação aos outros. Cada um dos dez tipos, a cada pesquisa confirmatória realizada, se mantinha nas posições que corroboravam o contraste dos valores de abertura à mudança com os de conservação e dos valores de autopromoção com os de autotranscendência.

As oposições entre tipos de valor em conflito podem ser resumidas concebendose os valores organizados em duas dimensões bipolares. Tal como se mostra na figura I, uma dimensão contrasta os valores de abertura à mudança com os de conservação. Essa dimensão opõe os que enfatizam a independência de julgamento e ação e favorecem a mudança (autodeterminação e estimulação) com aqueles que enfatizam a autorrepresão submissa, na preservação das práticas tradicionais e na proteção da estabilidade (segurança, conformidade e tradição). A segunda discussão contrasta os valores de autopromoção com os de autotranscendência. Essa dimensão opõe os valores que enfatizam a aceitação dos outros como iguais, assim como a preocupação com seu bem-estar (universalismo e benevolência) com aqueles que destacam a busca de sucesso pessoal e o domínio sobre os outros (poder e realização). O hedonismo está relacionado tanto com a abertura à mudança quanto a autopromoção. (Schwartz, 2006, p. 65).

Schwartz validou sua pesquisa com 96 amostras diferentes, conseguiu demostrar que uma mesma pessoa, raramente, poderia ter valores contrastantes ao mesmo tempo e no mesmo momento da vida. Entende-se que uma dimensão de autopromoção, que agrupa os valores de realização e poder, necessariamente, se opõe à dimensão de autotranscendência, que acopla os valores de benevolência e universalismo. Afinal, uma pessoa com a dimensão autotrancendência mais marcada tem como motivação critérios sociais, a possibilidade de ajudar os membros da sociedade e/ou do seu grupo e a busca de igualde e justiça social, enquanto a pessoa que possui a dimensão de autopromoção mais marcada, tem como motivação a realização de seus valores pessoais e a aquisição de poder em relação as pessoas. Uma 
mesma pessoa, sem estar em estado de conflito, não pode, ao mesmo tempo, buscar igualdade e justiça social e desejar poder sobre os outros.

Sendo assim, a estrutura de valores de Schwartz consegue identificar uma estrutura de valores e uma relação entre elas. Como já foi apresentado nesta pesquisa, os valores são preditores de ações e sua pesquisa auxilia na compreensão de prováveis comportamentos, mas também já se pôde observar ao longo dos estudos aqui apresentados que os valores podem ter características diferentes, quando se tratam de ramos específicos da vida, sendo assim, uma pessoa pode ter valores relativos a vida diferente dos valores que tem relativos ao trabalho.

O trabalho é uma das áreas fundamentais da vida dos indivíduos e tem sido um dos ramos sociais que sofreu mais modificações nos últimos séculos. Nesse âmbito a relação do homem com as organizações e com a sociedade tem se modificado.

Autores têm, ao longo das últimas décadas, estudado as relações entre valores pessoais e de trabalho. O objetivo principal desses estudos é compreender como se relacionam esses valores, considerando que são ramos diferentes com especificidades diferentes. Até no final dos anos 1990, a grande maioria dos autores trabalhava apenas com a hipótese de uma relação de difusão entre os dois âmbitos dos valores, no entanto, no final dos anos I990, pôde-se observar umas das primeiras recomendações de análises futuras considerando a relação baseada em compensação.

Duas hipóteses propostas alternativas sobre a natureza das relações entre trabalho e experiências não relacionadas ao trabalho foram sugeridas na literatura: difusão (ou seja, os dois tipos de experiências estão relacionados positivamente) e compensação (ou seja, relação negativa entre eles, Elizur, I99I). No entanto, os valores pessoais nos dois reinos, tradicionalmente, têm sido investigados em separado. O presente estudo oferece novas perspectivas na pesquisa de valores pessoais. Seria interessante analisar se o trabalho e os valores não relacionados ao trabalho estão relacionados entre si por relações difusão ou compensatórias. Por exemplo, a hipótese de difusão indica que aquele que procura a segurança do emprego também anseia por segurança na vida (por exemplo, a segurança econômica, segurança e falta de aventuras). Da mesma forma, difusão implica que fatores na qualidade de vida são semelhantes aos fatores na qualidade de vida no trabalho (Elizur \& Shye, 1990). A hipótese da compensação poderia indicar o contrário. Quase todas as correlações entre itens de vida e de trabalho no presente estudo foram positivas; Assim, os resultados tendem a suportar a hipótese de difusão, em invés da hipótese de compensação. No entanto, mais pesquisas neste tópico é recomendado. (Elizur, \& Sagie, I999, p. 85$)$.

\section{Revista Administração em Diálogo} ISSN 2178-0080 
Essa sugestão passou a ganhar força com os anos e a compreensão de que as relações dos indivíduos com o trabalho se modificaram. Compreender essa interrelação é importante para que se inicie um processo de compreensão sobre os modos de ação das pessoas nos atos de confluência e ou de divergência dos valores pessoais e laborais.

\section{Valores Laborais}

Os estudos de valores relativos ao trabalho têm papel importante na compreensão de algumas gamas de estudos, tem-se como referências principais os estudos preocupados com a valorização do trabalho e a busca por identificar quais são os valores do trabalho.

No que se refere aos estudos no campo de valores do trabalho, dois temas principais preocuparam os autores: I) o processo da valorização do trabalho em relação às demais esferas da vida e/ou em relação ao conjunto geral de valores humanos; e 2) a identificação dos valores do trabalho. (Tamayo, \& Borges, 2006, p. 400).

Compreender quais são os valores do trabalho pode auxiliar na compreensão de perfis, direcionadores de ação. Compreender se para determinada pessoa é valor no trabalho a autorrealização ou a busca por poder auxilia na compreensão de como as pessoas podem se posicionar em relação a questões que influenciem no trabalho.

Os estudos sobre o tema buscaram identificar valores específicos para o trabalho e possuíam na falta de universalismo do tema o seu maior limitador.

Algumas linhas de pesquisa questionaram os motivos que levam a separar os estudos de valores laborais dos estudos dos valores específicos. Uma das principais razões para esta mudança é o motivo de que as relações e interpretações mudam quando assuntos específicos são tratados e quando contextos são considerados.

Como valores são compreendidos como estruturas gerais que guiam o comportamento das pessoas, Stackman apropriadamente se pergunta qual o benefício (claridade conceitual, insights aplicados ou qualquer utilidade científica) em distinguir valores gerais de valores para contextos específicos. Para ele, a identificação de valores em contextos específicos deve ser considerada, pois os valores podem assumir maior ou menor importância a depender do contexto e do tempo. Da mesma forma, Elizur e Sagie defenderam que os valores possuem diversas facetas, dependendo da sua relação com um contexto específico, como é o caso dos valores laborais. Portanto, os valores em contextos específicos não têm o objetivo de revelar os valores básicos do indivíduo, mas de

\section{Revista Administração em Diálogo} ISSN 2178-0080 
clarificar diferenças entre pessoas e culturas que podem surgir quando valores são expressos em julgamentos e comportamentos específicos. Assim, a identificação e estudo dos valores no ambiente de trabalho podem dar insights sobre a aplicação do conceito de valores no ambiente de trabalho, além de possibilitarem uma melhor compreensão do impacto desse conceito sobre atitudes e comportamento no trabalho. (Porto, 2008, p. I79).

Sendo, assim o estudo sobre o tema possibilita algumas reflexões e insights importantes.

Algumas definições de valores de trabalho apareceram ao longo dos anos como fruto das pesquisas realizadas, como pode-se observar na Figura 3 :

\begin{tabular}{|c|c|}
\hline Autor & Definição \\
\hline $\begin{array}{l}\text { Samuel \& Lewin-Epstein } \\
\text { (1979) }\end{array}$ & $\begin{array}{l}\text { Valores laborais são aqueles que determinam os modos, } \\
\text { meios, comportamentos ou os resultados que são preferíveis } \\
\text { sobre outros. }\end{array}$ \\
\hline Nord et al (1998) & $\begin{array}{l}\text { Valores laborais são estados de existência desejados pelas } \\
\text { pessoas e que são sentidos como possíveis de realização } \\
\text { por meio do trabalho. }\end{array}$ \\
\hline Hofstede (1997) & $\begin{array}{l}\text { Valores são uma tendência geral para preferir certo estado } \\
\text { de coisas a outro. }\end{array}$ \\
\hline Dose (1997) & $\begin{array}{l}\text { Valores do trabalho são padrões avaliativos relativos ao } \\
\text { trabalho e ao contexto de trabalho por meio dos quais o } \\
\text { indivíduo discerne o que é "certo" ou acessa a importância } \\
\text { das referências. }\end{array}$ \\
\hline Sagie \& Elizur (1996) & $\begin{array}{l}\text { Valores laborais definem-se com } 00 \text { a importância dada pelos } \\
\text { indivíduos a certos resultados obtidos no contexto do } \\
\text { trabalho. }\end{array}$ \\
\hline Schwartz (1999) & $\begin{array}{l}\text { Valores laborais referem-se a metas ou recompensas que as } \\
\text { pessoas buscam por meio do trabalho }\end{array}$ \\
\hline $\begin{array}{l}\text { Ros, Schwartz \& Surkiss } \\
(1999)\end{array}$ & $\begin{array}{l}\text { Valores laborais são princípios ou crenças sobre } \\
\text { comportamentos ou metas desejáveis, hierarquicamente } \\
\text { organizados, que guiam as avaliações sobre os resultados e } \\
\text { contexto do trabalho, bem como a escolha de alternativas de } \\
\text { trabalho. }\end{array}$ \\
\hline Porto \& Tamayo (2003) & $\begin{array}{l}\text { Valores do trabalho são princípios ou crenças sobre metas } \\
\text { ou recompensas desejáveis, hierarquicamente organizados, } \\
\text { que as pessoas buscam por meio do trabalho e que guiam } \\
\text { suas avaliações sobre os resultados e contexto do trabalho, } \\
\text { bem como o seu comportamento e a escolha de alternativas } \\
\text { de trabalho. }\end{array}$ \\
\hline
\end{tabular}

Figura 3-Definições de valores do trabalho.

Fonte: Porto (2008, p. 18I).

De I979 até 2003, passou-se por uma modificação no modo de entender e conceituar os valores laborais. Em 1979, entendia-se os valores laborais como determinante para se preferir modos, comportamentos ou resultados, já em I996 os valores passam a ser a importância atribuída, por cada indivíduo, a certos resultados

\section{Revista Administração em Diálogo}

ISSN 2178-0080 
obtidos no trabalho. Em 1997 duas definições diferentes foram propagadas, uma definia-o como uma tendência geral para preferir certo estado de coisas, a outra o definia como padrões avaliativos relativos ao trabalho. Em 1998 ele passa a ser compreendido como um estado de existência desejado pelas pessoas e realizado por meio do trabalho.

Em 1999, surge a definição de Ros, Schwartz e Surkiss (I999), que é a mais difundida, que entende o Valor Laboral como princípio ou crença, sobre comportamentos ou metas desejáveis, hierarquicamente organizados, que guiam avaliações sobre os resultados e contexto do trabalho, bem como a escolha de alternativas de trabalho. A definição mais atual, difundida no Brasil, apresenta algumas adequações de termos interessantes e que atualizam alguns dos aspectos relativos aos valores laborais

Entender valores pode auxiliar na compreensão dos rumos pelos quais as pessoas optam quando se relacionam com contexto e resultados laborais e com suas alternativas. São inúmeros os trabalhos buscando a compreensão, categorização ou definição dos valores laborais, mas foi a partir dos anos I990 que se optou pela relação dos valores laborais com a teoria de Schwartz.

Anteriormente, foram desenvolvidos diversos modelos teóricos para compreensão de fenômeno, mas somente a partir de I99o surgiram esforços para compreender os valores do trabalho a partir de teorias sobre valores gerais. Porto e Tamayo defendem que os modelos que apresentam melhor fundamentação são as teorias de Elizur e a de Ros e outros, sendo que esta última está baseada em uma das principais teorias sobre valores humanos da atualidade, a teoria de Schwartz. Nos últimos anos os autores parecem convergir para o uso desta teoria na compreensão dos valores do trabalho e são encontrados alguns trabalhos que desenvolveram escalas de medida nessa direção. (Porto, 2008, p. I77).

A utilização da teoria dos valores de Schwartz possibilita uma perspectiva universalista e de aproximação com outras áreas de pesquisa. A estruturação da temática tem possibilitado um amadurecimento dos estudos sobre o tema.

A pesquisa de Ros et. al. (I999) é a primeira que aplica a teoria de Schwartz e busca um sincronismo teórico. A pesquisa corrobora a perspectiva da teoria de Schwartz quando apresenta uma correlação entre a estrutura de segunda ordem e os dois eixos bipolares. 
Em 1999, Ros e outros interessam-se por aplicar esse modelo aos estudos de valores do trabalho, fazendo uma ampla revisão da literatura, e percebem que os estudos de valores laborais não têm considerado o desenvolvimento teórico da área de valores, propondo assim a aplicação da teoria de Schwartz (1992) a eles, uma vez que os valores do trabalho são expressões, em um contexto específico, dos valores gerais. A pesquisa de Ros e outros utilizou a estrutura de segunda ordem com os dois eixos bipolares. Os resultados da análise fatorial exploratória e do SSA corroboram a estrutura de quatro fatores assim identificados: I) intrínseco - refere-se a metas obtidas pelo conteúdo do próprio trabalho; 2) extrínseco - refere-se a metas obtidas pelos resultados do trabalho; 3 ) social refere-se à busca de metas relacionadas; e 4) prestígio - refere-se à busca de poder e prestígio por meio do trabalho. A dinâmica de incompatibilidade entre valores extrínsecos e intrínsecos, bem como para prestigio e social, também foi corroborada. (Porto, 2008, p. 185).

Quanto à perspectiva dos valores laborais, no Brasil, Porto e Tamayo (2003) desenvolveram e validaram uma escala de valores. Para que a escala fosse construída, os autores realizaram um levantamento dos instrumentos publicados e entrevistaram trabalhadores. Chegou-se a quatro fatores, conforme previsto teoricamente por Ros et al. (I999), e atribuiu-se as seguintes denominações:

I) Realização profissional: Refere-se à busca de prazer e realização pessoal e profissional, bem como de independência de pensamento e ação no trabalho, por meio da autonomia intelectual e da criatividade;

2) Estabilidade: refere-se à busca de segurança e ordem na vida, por meio do trabalho, possibilitando suprir materialmente as necessidades pessoais;

3) Relações sociais: Refere-se à busca de relações sociais positivas no trabalho e de contribuição positiva para a sociedade, por meio do trabalho;

4) Prestígio: Refere-se à busca de autoridade, sucesso profissional e poder de influência no trabalho.

Os fatores encontrados nos estudos nacionais se encaixam na proposta de Ros et. al. (I999), e são, comumente, a opção dos pesquisadores nacionais sobre o tema, por terem minimizado as incongruências do idioma e da compreensão de algumas questões relativas a cultura. A escala elaborada auxilia na identificação dos valores relativos ao trabalho e possibilita a compreensão dos preditivos para determinadas ações. A utilização da proposta alinhada com a teoria de valores de Schwartz propicia a verificação de confluências e divergências entre os valores pessoais e valores laborais.

\section{Revista Administração em Diálogo} ISSN 2178-0080 
A proposta de utilizar a teoria de valores de Schwartz para compreender as estruturas dos valores organizacionais e do trabalho também traz como vantagem a possibilidade de comparação das medidas e de estabelecer o nível de congruência entre o indivíduo e a organização. Se os estudos sobre congruência são corretos, é de se esperar que os valores do trabalho influenciem a preferência por aspectos do contexto organizacional, e a congruência entre o contexto preferido e o real influencia os resultados do trabalho, como os comportamentos de cidadania organizacional, comprometimento, satisfação e bem-estar no trabalho. Pesquisas futuras devem focar nessas relações para que possamos desenvolver uma compreensão mais ampla da forma como os desejos das pessoas influenciam na realização do trabalho e para que possamos propor ações organizacionais em sintonia com esses valores. (Porto, 20o8, p. 196).

Considerando a construção dos dois parâmetros de valores, pode-se entender que a compreensão dos valores pessoais auxilia na caracterização de aspectos da vida, e a compreensão de valores laborais auxilia na caracterização de posicionamentos no trabalho.

\section{Apresentação e Análise de Dados}

\section{Apresentação}

A presente pesquisa foi realizada para o doutoramento desta pesquisadora e teve como população alvo universitários da cidade de São Paulo, com faixa etária entre I6 e 45 anos. Os questionários foram aplicados em quatro universidades diferentes: PUC-SP, Centro Universitário Senac, Centro Universitário Adventista de SP e Universidade Anhanguera de São Paulo, objetivando uma maior variabilidade de informações e perfis.

Foram distribuídos $5^{60}$ questionários. Destes, $5^{23}$ foram respondidos e 54 foram considerados válidos. Obtendo-se assim uma taxa de resposta de 97,7\%. Foram descartados todos os questionários que apresentavam mais de dez itens em branco.

Sendo assim, a pesquisa foi realizada com base nas respostas de $5^{\mathrm{I}} 4$ estudantes, sendo que, destes, $54,86 \%$ são do sexo feminino e 45,I4\% são do sexo masculino. A maioria da amostra $\left(5^{8,56 \%)}\right.$ tem entre 20 e 25 anos. 
Tabela I - Dados demográficos.

\begin{tabular}{lcc}
\hline \multicolumn{1}{c}{$\begin{array}{c}\text { Variáveis } \\
\text { Demográficas }\end{array}$} & Quantidade & $\%$ \\
\hline $\begin{array}{l}\text { Feminino } \\
\text { Masculino }\end{array}$ & 282 & $54,86 \%$ \\
& 232 & $45,14 \%$ \\
$\begin{array}{l}\text { Faixa etária de 16 a } 19 \\
\text { anos }\end{array}$ & 73 & $14,20 \%$ \\
$\begin{array}{l}\text { Faixa etária de 20 a } 25 \\
\text { anos }\end{array}$ & 301 & $58,56 \%$ \\
$\begin{array}{l}\text { Faixa etária de 26 a } 30 \\
\text { anos }\end{array}$ & 70 & $13,62 \%$ \\
$\begin{array}{l}\text { Faixa etária de 31 a } 35 \\
\text { anos }\end{array}$ & 39 & $7,59 \%$ \\
$\begin{array}{l}\text { Faixa etária de } 36 \text { a } 40 \\
\text { anos }\end{array}$ & 15 & $2,92 \%$ \\
$\begin{array}{l}\text { Faixa etária de } 41 \text { a } 45 \\
\text { anos }\end{array}$ & 16 & $3,11 \%$ \\
\hline
\end{tabular}

Fonte: Elaborado pela autora.

Quanto aos procedimentos, a coleta de dados foi realizada pela pesquisadora, em parceria com seis professores universitários. Todos os professores aplicadores dos questionários foram devidamente orientados, segundo as observações realizadas durante o pré-teste.

Os professores responsáveis pela aplicação dos questionários visitaram as salas e convidaram os alunos a participar da pesquisa, esclarecendo que a participação não era obrigatória, no entanto, evidenciando a importância da participação de todos e explicitando a relevância da pesquisa.

Os instrumentos foram entregues em um único caderno contendo sete páginas, impressas frente e verso, sendo a primeira página dedicada a carta de apresentação e explicações sobre o questionário e a pesquisa, o restante do caderno de questões foi dividido em três seções.

A primeira seção, contendo duas questões, é dedicada aos dados demográficos relativos a idade e gênero, a segunda seção, com foco nos valores pessoais, é composta por uma explicação de como se deve proceder em relação à pontuação atribuída a cada um dos quesitos e o conjunto de 2I questões relativas ao Portrait Value Questionnaire (PVQ), a terceira seção se dedica à investigação dos valores laborais e é composta por uma explicação de como proceder em relação à escala e o conjunto de 45 questões relativas aos valores laborais. 
Os questionários foram distribuídos em i2 turmas diferentes e cada respondente utilizou um período de 20 a 3omin para preencher os questionários. Após respondidos os questionários, foram recolhidos, numerados e agrupados para as devidas análises. Posteriormente, os dados coletados foram tabulados no Excel e transpostos para o programa estatístico SPSS (Statistical Package of Social Science) para as devidas análises e avaliações.

As análises e avaliações foram realizadas através do Alfa de Cronbach, Comparação de Médias e Regressão Linear. A avaliação da consistência interna foi verificada pelo cálculo do coeficiente alfa de Cronbach. Os valores de $\alpha$ variam de o a I,o e quanto mais próximo de I maior é a confiabilidade dos indicadores.

Na presente pesquisa o coeficiente Alfa de Cronbach teve valor geral em o,828, comprovando sua confiabilidade. Optou-se por verificar os $\alpha$ de cada uma das variáveis. As definições para cada tipo motivacional e seu respectivo Alfa de Cronbach podem ser observados na Tabela 2.

Tabela 2 - Tipos motivacionais, Alfa de Cronbach

\begin{tabular}{|c|c|c|}
\hline $\begin{array}{c}\text { Tipo } \\
\text { Motivacional }\end{array}$ & Definição & $\begin{array}{c}\text { Alfa de } \\
\text { Cronbach }\end{array}$ \\
\hline Poder & Status social sobre as pessoas e os recursos. & 0,819 \\
\hline Realização & $\begin{array}{l}\text { Sucesso pessoal mediante a demonstração de } \\
\text { competência, segundo critérios sociais. }\end{array}$ & 0,819 \\
\hline Hedonismo & Prazer e gratificação para si mesmo. & 0,816 \\
\hline Estimulação & Entusiasmo, novidade e desafio na via. & 0,820 \\
\hline Autodeterminação & $\begin{array}{l}\text { Pensamento independente e escolha da ação, } \\
\text { criatividade, exploração. }\end{array}$ & 0,823 \\
\hline Universalismo & $\begin{array}{l}\text { Compreensão, apreço, tolerância e atenção com o } \\
\text { bem-estar de todas as pessoas e da natureza. }\end{array}$ & 0,821 \\
\hline Benevolência & $\begin{array}{c}\text { Preservação ou intensificação do bem-estar das } \\
\text { pessoas com as quais se está em contato pessoal } \\
\text { frequente. }\end{array}$ & 0,819 \\
\hline Tradição & $\begin{array}{l}\text { Respeito, compromisso e aceitação dos costumes e } \\
\text { ideias oferecidas pela cultura tradicional ou a religião. }\end{array}$ & 0,828 \\
\hline Conformidade & $\begin{array}{c}\text { Restrição das ações, tendências e impulsos que } \\
\text { possam incomodar ou ferir os outros e contrariar } \\
\text { expectativas ou normas sociais. }\end{array}$ & 0,824 \\
\hline Segurança & $\begin{array}{l}\text { Segurança, harmonia e estabilidade da sociedade, das } \\
\text { relações e de si mesmo. }\end{array}$ & 0,806 \\
\hline
\end{tabular}

Fonte: Elaborado pela autora.

\section{Revista Administração em Diálogo} ISSN 2178-0080 
Todos os tipos motivacionais apresentaram Alfa de Cronbach superior a o,8oo, tendo como maior Alfa de Cronbach o item tradição com o,828 e menor Alfa de Cronbach o item segurança com o,806. Esses valores representam um grau aceitável de consistência dos dados considerando que quanto mais próximo der maior a confiabilidade dos indicadores.

O próximo conjunto de variáveis analisadas foram as relativas aos valores laborais que formam quatro tipos básicos de valor laboral. As definições de cada valor laboral e seu respectivo Alfa de Cronbach podem ser observados na Tabela 3.

Tabela 3 - Valor laboral, Alfa de Cronbach

\begin{tabular}{lcc}
\hline Valor Laboral & \multicolumn{1}{c}{ Definição } & $\begin{array}{c}\text { Alfa de } \\
\text { Cronbach }\end{array}$ \\
\hline $\begin{array}{l}\text { Realização } \\
\text { Profissional }\end{array}$ & $\begin{array}{c}\text { Refere-se à busca de prazer e realização pessoal e } \\
\text { profissional, bem como de independência de } \\
\text { pensamento e ação no trabalho, por meio da } \\
\text { autonomia intelectual e da criatividade. }\end{array}$ & 0,822 \\
Estabilidade & $\begin{array}{l}\text { Refere-se à busca de segurança e ordem na vida por } \\
\text { meio do trabalho, possibilitando suprir materialmente } \\
\text { as necessidades pessoais. }\end{array}$ & 0,823 \\
Relações sociais & $\begin{array}{r}\text { Refere-se à busca de relações sociais positivas no } \\
\text { trabalho e de contribuição positiva para a sociedade, } \\
\text { por meio do trabalho. }\end{array}$ & 0,820 \\
Prestígio & $\begin{array}{r}\text { Refere-se à busca de autoridade, sucesso profissional } \\
\text { e poder de influência no trabalho. }\end{array}$ & 0,820 \\
\hline
\end{tabular}

Fonte: Elaborado pela autora.

Observando a Tabela 3, pode-se verificar que todos os valores laborais analisados apresentaram Alfa de Cronbach superior ou igual a o,82O, o que representa grau aceitável de consistência dos dados, considerando que a proximidade com I determina a confiabilidade do indicador.

Após a realização do teste supracitado, passa-se à realização da verificação das hierarquias formadas por cada um dos elementos envolvidos no processo, segundo a análise das médias geradas pelas respostas das escalas. A Tabela 4 apresenta a hierarquia dos valores pessoais. 
Tabela 4 - Hierarquia Valores Pessoais

\begin{tabular}{lcc}
\hline \multicolumn{1}{c}{ Posição } & Média & Desvio padrão \\
\hline Universalismo & 5,67 & 1,43 \\
Hedonismo & 5,57 & 1,47 \\
Benevolência & 5,44 & 1,48 \\
Estimulação & 5,00 & 1,73 \\
Autodeterminação & 4,74 & 1,46 \\
Segurança & 3,95 & 1,79 \\
Realização & 3,89 & 2,20 \\
Conformidade & 3,79 & 1,85 \\
Tradição & 3,38 & 1,94 \\
Poder & 2,76 & 1,86 \\
\hline
\end{tabular}

Fonte: Elaborado pela autora.

A hierarquia dos valores pessoais tem como item com maior média o universalismo, em segundo hedonismo e em terceiro benevolência. Universalismo e benevolência sempre apareceram em posições de destaque em pesquisas nacionais sobre valores pessoais, como se pode observar em Jesus (2006): o universalismo teve uma média de 4,o6 e ficou na posição 2, enquanto a benevolência teve uma média de 4,IO e ficou na posição I. Na pesquisa elaborada por Jesus (2006), comparou-se os dados de Porto (2004) com os dados coletados naquele momento. Comparando os dados coletados naquele momento com os atuais, pode-se observar que algumas posições não são surpresas no ranking nacional.

Tabela 5-Comparação

\begin{tabular}{lccc}
\hline \multicolumn{1}{c}{ Posição } & $\begin{array}{c}\text { Amostra } \\
\text { Atual }\end{array}$ & Jesus (2006) & Porto (2004) \\
\hline Universalismo & $5,67(1,43)$ & $4,06(0,76)(2)$ & $5,01(0,83)(4)$ \\
Hedonismo & $5,57(1,47)$ & $3,35(1,14)(6)$ & $5,01(1,32)(5)$ \\
Benevolência & $5,44(1,48)$ & $4,10(0,76)(1)$ & $5,41(0,74)(1)$ \\
Estimulação & $5,00(1,73)$ & $2,92(1,17)(8)$ & $3,67(1,45)(9)$ \\
Autodeterminação & $4,74(1,46)$ & $3,98(0,84)(3)$ & $5,06(0,87)(3)$ \\
Segurança & $3,95(1,79)$ & $3,67(0,89)(4)$ & $5,11(0,92)(2)$ \\
Realização & $3,89(2,20)$ & $2,86(1,11)(9)$ & $4,22(1,03)(7)$ \\
Conformidade & $3,79(1,85)$ & $3,50(0,90)(5)$ & $4,75(1,02)(6)$ \\
Tradição & $3,38(1,94)$ & $3,02(0,89)(7)$ & $3,78(1,22)(8)$ \\
Poder & $2,76(1,86)$ & $2,30(1,16)(10)$ & $2,92(1,06)(10)$ \\
\hline
\end{tabular}

Fonte: Elaborado pela autora.

Como se pode observar na comparação entre as pesquisas, a modificação mais conscistente relativa aos rankins é o hedonismo, que ocupava a quinta posição na

\section{Revista Administração em Diálogo} ISSN 2178-0080 
pesquisa de Porto (2004) e a sexta posição na pesquisa de Jesus (2006). Outro ponto que merece destaque é o item segurança, que já esteve em segundo lugar na pesquisa de Porto (2004) e, na pesquisa de Jesus (2006), ocupou a quarta posição, na amostra atual passou a ocupar apenas a sexta posição. Por outro lado o valor pessoal poder ocupa a última posição nas três pesquisas.

A hierarquia gerada pelas médias dos pontos atribuídos aos valores laborais é apresentada na Tabela 6 .

Tabela 6 - Hierarquia de Valores Laborais

\begin{tabular}{lcc}
\hline \multicolumn{1}{c}{ Posição } & Média & Desvio padrão \\
\hline Estabilidade & 4,23 & 0,56 \\
Realizações & 4,17 & 0,54 \\
Profissional & & \\
Relações & 3,77 & 0,65 \\
Sociais & 2,90 & 0,78 \\
Prestígio & & \\
\hline
\end{tabular}

Fonte: Elaborado pela autora.

O principal valor laboral, identificado pelos universitários de São Paulo que responderam a presente pesquisa, é estabilidade, seguido de perto por realização profissional. $\mathrm{O}$ valor laboral com menor média foi prestígio.

Quando compara-se os resultados atuais com as pesquisas realizadas anteriormente, como feito por (Jesus, 20o6), tem-se a perspectiva apresentada na Tabela 7 .

Tabela 7 - Comparação

\begin{tabular}{lccc}
\hline \multicolumn{1}{c}{ Posição } & $\begin{array}{c}\text { Amostra } \\
\text { Atual }\end{array}$ & Jesus (2006) & Porto (2004) \\
\hline Estabilidade & $4,23(0,56)$ & $4,2(0,51)(2)$ & $4,1(0,51)(2)$ \\
$\begin{array}{l}\text { Realizações } \\
\text { Profissional }\end{array}$ & $4,17(0,54)$ & $4,3(0,50)(1)$ & $4,5(0,41)(1)$ \\
$\begin{array}{l}\text { Relações } \\
\text { Sociais }\end{array}$ & $3,77(0,65)$ & $3,9(0,57)(3)$ & $3,7(0,65)(3)$ \\
Prestígio & $2,90(0,78)$ & $2,9(0,80)(4)$ & $2,5(0,65)(4)$ \\
\hline
\end{tabular}

Fonte: Elaborado pela autora.

Pode-se observar que nas duas pesquisas anteriores, realização profissional ocupou o primeiro lugar na hierarquia dos valores laborais e a estabilidade ocupava o

\section{Revista Administração em Diálogo} ISSN 2178-0080 
segundo lugar. Na amostra atual, essa posição se inverteu, os universitários que responderam ao questionário apresentaram a estabilidade como principal valor laboral.

A Tabela 8 apresenta os dados de correlações relativos aos valores pessoais e aos laborais.

Tabela 8 - Correlações entre valores Pessoais e Laborais

\begin{tabular}{|c|c|c|c|c|c|c|c|c|c|}
\hline & & Conservação & $\begin{array}{c}\text { Abertura a } \\
\text { mudança }\end{array}$ & $\begin{array}{c}\text { Auto } \\
\text { Transcendência }\end{array}$ & $\begin{array}{c}\text { Auto } \\
\text { Promoção }\end{array}$ & $\begin{array}{c}\mathrm{VL}_{-} \\
\text {Estab }\end{array}$ & $\begin{array}{c}\text { VL_Real_ } \\
\text { Soc }\end{array}$ & $\begin{array}{l}\mathrm{VL}_{-} \\
\text {Real } \\
\end{array}$ & $\begin{array}{l}\text { VL } \\
\text { Prest } \\
\end{array}$ \\
\hline \multirow{2}{*}{ Conservação } & C. Pearson & 1 & $0,307^{* *}$ & $0,450^{* *}$ & $0,406^{* *}$ & $0,266^{* *}$ & $0,432^{2 *+}$ & $0,273^{* *}$ & $0,317^{* *}$ \\
\hline & Sig. ${ }^{*}$ & & 0,000 & 0,000 & 0,000 & 0,000 & 0,000 & 0,000 & 0,000 \\
\hline \multirow{2}{*}{$\begin{array}{l}\text { Abertura a } \\
\text { mudança }\end{array}$} & C. Pearson & $0,307^{* *}$ & 1 & $0,506^{* *}$ & $0,603^{* *}$ & $0,281^{* *}$ & $0,359^{* *}$ & $0,398^{* *}$ & $0,191^{* *}$ \\
\hline & Sig. ${ }^{*}$ & 0,000 & & 0,000 & 0,000 & 0,000 & 0,000 & 0,000 & 0,000 \\
\hline \multirow{2}{*}{$\begin{array}{l}\text { Auto } \\
\text { Transcendência }\end{array}$} & C. Pearson & $0,450^{* *}$ & $0,506^{* *}$ & 1 & $0,257^{* *}$ & $0,240^{* *}$ & $0,514^{* *}$ & $0,369^{* *}$ & 0,016 \\
\hline & Sig. ${ }^{*}$ & 0,000 & 0,000 & & 0,000 & 0,000 & 0,000 & 0,000 & 0,713 \\
\hline \multirow{2}{*}{ Auto Promoção } & C. Pearson & $0,406^{* *}$ & $0,603^{* *}$ & $0,257^{* *}$ & 1 & $0,384^{* *}$ & $0,305^{* *}$ & $0,358^{* *}$ & $0,539^{* * *}$ \\
\hline & Sig.* & 0,000 & 0,000 & 0,000 & & 0,000 & 0,000 & 0,000 & 0,000 \\
\hline \multirow{2}{*}{ VL_Estab } & C. Pearson & $0,266^{* *}$ & $0,281^{* *}$ & $0,240^{* *}$ & $0,384^{* *}$ & 1 & $0,419^{* *}$ & $0,489^{* *}$ & $0,432^{* *}$ \\
\hline & Sig.* & 0,000 & 0,000 & 0,000 & 0,000 & & 0,000 & 0,000 & 0,000 \\
\hline \multirow{2}{*}{ VL_Real_Soc } & C. Pearson & $0,432^{* *}$ & $0,359^{* *}$ & $0,514^{* *}$ & $0,305^{* *}$ & $0,419^{* *}$ & 1 & $0,658^{* *}$ & $0,426^{* *}$ \\
\hline & Sig. ${ }^{*}$ & 0,000 & 0,000 & 0,000 & 0,000 & 0,000 & & 0,000 & 0,000 \\
\hline \multirow{2}{*}{ VL_Real } & C. Pearson & $0,273^{* *}$ & $0,398^{* *}$ & $0,369^{* *}$ & $0,358^{* *}$ & $0,489^{* *}$ & $0,658^{* *}$ & 1 & $0,456^{* *}$ \\
\hline & Sig. ${ }^{*}$ & 0,000 & 0,000 & 0,000 & 0,000 & 0,000 & 0,000 & & 0,000 \\
\hline \multirow{2}{*}{ VL_Prest } & C. Pearson & $0,317^{* *}$ & $0,191^{* *}$ & 0,016 & $0,539^{* *}$ & $0,432^{* *}$ & $0,426^{* *}$ & $0,456^{* *}$ & 1 \\
\hline & Sig. ${ }^{*}$ & 0,000 & 0,000 & 0,713 & 0,000 & 0,000 & 0,000 & 0,000 & \\
\hline
\end{tabular}

Fonte: Elaborado pela autora.

* 2 extremidades

Observando as correlações apresentadas na Tabela ıo, tem-se que as correlações positivas, comumente estabelecidas e atribuídas às inter-relações dos valores pessoais e laborais, se mantiveram. O valor laboral realização profissional teve correlação positiva com o valor pessoal abertura a mudança com o,398. O valor laboral relação social teve correlação positiva com o valor pessoal autotranscendencia com 0,544. O valor laboral prestígio teve correlação positiva com o valor pessoal autopromoção com 0,539. O valor laboral estabilidade teve correlação positiva com o valor pessoal conservação com 0,266.

Quanto as correlações negativas comumente apresentadas nos estudos sobre esse tema, nesta pesquisa, nenhuma se confirmou. O valor laboral realização profissional teve correlação positiva com o valor pessoal conservação de o,432. O valor pessoal estabilidade teve correlação positiva com abertura a mudança o,28I. O valor

\section{Revista Administração em Diálogo} ISSN 2178-0080 
laboral relações sociais teve correlação positiva com o valor pessoal autopromoção 0,305. O valor laboral prestígio teve correlação positiva com o valor pessoal autotrancendência o,oI6.

Esses dados não são surpreendentes, considerando que, em estudos como o de Porto e Tamayo (2007), as hipóteses relativas às relações conflitantes entre os valores não foram comprovadas. Sendo assim, entende-se que se a inter-relação dos valores pessoais e laborais gera valores negativos, significando que são valores conflitantes, mas que os individuos não estão em conflito, afinal eles não estão contidos na mesma pessoa. Por outro lado, os valores positivos, dentro de uma amostra, indicam que os indivíduos estão com conflitos individuais relativos aos valores pessoais e laborais, ou seja, possuem valores com orientações divergentes, agindo conjuntamente.

\section{Considerações Finais}

Este trabalho de pesquisa teve como objetivo geral caracterizar as interrelações entre valores pessoais e laborais de jovens universitários na cidade de São Paulo.

As teorias de inter-relação entre os valores pessoais e laborais identificam polos entre os dois tipos de valores, que são consonantes e conflitantes. Segundo a pesquisa realizada, identificou-se os consonantes: valor laboral realização profissional e abertura a mudança, valor laboral relações pessoais e valor pessoal autotranscedência, valor laboral prestígio e valor pessoal autopromoção, valor laboral estabilidade e valor pessoal conservação, e os conflitantes: valor laboral realização profissional e valor pessoal conservação, valor laboral estabilidade e valor pessoal abertura a mudança, valor laboral relação social e valor pessoal autopromoção e valor laboral prestígio e valor pessoal autotranscedência.

No entanto, a análise da amostra possibilitou observar que as correlações entre esses valores foram todas positivas, ou seja, diante desta análise, as inter-relações de consonância, que mostram que alguns valores, quando importantes na vida, também são importantes no âmbito profissional, foram comprovadas; e as inter-relações que demonstram que alguns valores, quando importantes na vida, excluem a existência de alguns valores relativos ao âmbito do trabalho, por serem opostos aos valores 
apresentados nos direcionadores de comportamento na vida, foram refutadas e confirmada a perspectiva de que os valores podem coexistir estando em estados de conflito.

Essa inter-relação positiva mostra que, em alguns casos, os indivíduos nutrem valores profissionais conflitantes com os valores que lhes direcionam a vida. Como são valores divergentes podem colocar os indivíduos em situações de conflitos individuais, por exemplo, se de um lado se pretende ter realização profissional, por outro lado se tem valores latentes de conservação que agrega tradição, conformidade e segurança. Sendo assim, em alguns momentos, para que o indivíduo possa buscar o seu valor laboral de realização profissional, ele tem de abandonar o seu valor pessoal de conformismo, ou vice-versa.

\section{Referências}

Almeida, F. J. R., \& Sobral, F. B. A. (2009) O sistema de valores humanos de administradores brasileiros: adaptação da escala PVQ para o estudo de valores no Brasil. Revista de Administração Mackenzie, Io(3).

Castro Solano, A., \& Nader, M. La evaluación de los valores humanos com el Portrait Values Questionnaire de Schwartz. Interdisciplinaria, 23(2).

Elizur, D., \& Sagie, A. (r999). Facets of personal values: A structural analysis of life and work values.Applied Psychology: An International Review, 48, 73-87.

Porto, J. B. (2008). Valores do trabalho e seu impacto sobre atitudes e comportamento no trabalho. In: M. L. M. Teixeira (Org.). Valores Humanos \& Gestão: Novas Perspectivas. São Paulo: Editora Senac.

Porto, J. B., \& Tamayo, A. (2003). Escala de valores do trabalho: EVT. Psicologia: Teoria e Pesquisa, I9(2).

Porto, J. B., \& Tamayo, A. (2007). Estrutura dos Valores Pessoais: A relação entre valores Gerais e Laborais. Psicologia: Teoria e Pesquisa, 23(I).

Rokeach, M. (i973). The Nature of human Value. Nova York: Free Press.

Ros, M. (2006). Psicologia social dos valores: uma perspectiva histórica. In: M. Ros, \& V. Gouveia (Orgs.). Psicologia social dos valores humanos: Desenvolvimentos teóricos, metodológicos e aplicados. São Paulo: Editora Senac.

Ros, M., Schwartz, S. H., \& Surkiss, S. (1999) Basic individual values, work values, and the meaning of work [Special issue]. Applied Psychology: An International Review, 48, 49-7I.

Sagie, A., \& Elizur, D. (I996). The structure of personal values: a conical representation of múltiple life areas. Journal of Organizational Behavior, I7, 573-586. 
Schwartz, S. H., \& Bilsky, W. (1987). Toward a universal psychological structure of human values. Journal of Personality and Social Psychology, 53, 550-562.

Schwartz, S. H. (1992). Universals in the content and structure of values: Theoretical advances and empirical tests in 20 countries. In: Zanna, M. P. (Org.). Advances in experimental social psychology. San Diego: Academic.

Schwartz, S. H. (2006) Há aspectos universais na estrutura e no conteúdo dos valores humanos?. In: M. Ros, \& V. Gouveia (Orgs.). Psicologia social dos valores humanos: Desenvolvimentos teóricos, metodológicos e aplicados. São Paulo: Editora Senac.

Tamayo, Á., \& Borges, L. de O. (2006). Valores do trabalho e das organizações. In: M. Ros, \& V. Gouveia (Orgs.). Psicologia social dos valores humanos: Desenvolvimentos teóricos, metodológicos e aplicados. São Paulo: Editora Senac. 